\title{
Blood eosinophil counts in COPD patients compared to controls
}

\begin{abstract}
To the Editor:
In patients with COPD, blood eosinophil counts can predict the effects of inhaled corticosteroids (ICS) on exacerbation rates [1-4]. Blood eosinophil counts are now recommended by the Global initiative for the management of Obstructive Lung Disease (GOLD) as a biomarker to help guide ICS use in clinical practice [5].

It is estimated up to $40 \%$ of COPD patients have increased numbers of eosinophils in the sputum $[6,7]$. There is also an association between lung and blood eosinophil counts [8-11], and blood eosinophil counts have been used as a surrogate marker for eosinophil numbers in the lungs [12]. However, it is not clear whether COPD peripheral blood eosinophil counts are increased above levels observed in healthy controls. If true, this would implicate systemic eosinophilia in COPD as a cause of increased lung eosinophils in COPD patients. We tested the hypothesis that peripheral blood eosinophil counts are raised in COPD patients by retrospectively analysing blood eosinophil counts collected from COPD patients and older healthy controls (age $>40$ years) at our research centre.
\end{abstract}

Results from COPD patients ( $\mathrm{n}=209$ ), healthy smokers (HS; $\mathrm{n}=46$ ) and healthy nonsmokers (HNS; $\mathrm{n}=81$ ) aged $\geqslant 40$ years who participated in research studies at the Medicines Evaluation Unit (Manchester University NHS Hospitals Trust, Manchester, UK) were used. COPD was diagnosed according to GOLD recommendations [13] and subjects with a previous clinical diagnosis of any asthma were excluded. All healthy subjects had normal spirometry. COPD patients and HS had smoking history $\geqslant 10$ pack-years. Subjects taking oral corticosteroids were excluded. All subjects provided blood samples $>4$ weeks from exacerbations or colds. This research was approved by the local Ethics Committees; all subjects provided written informed consent.

Blood eosinophil measurements (reported to an accuracy of 10 cells $\mu \mathrm{L}^{-1}$ ) were performed by The Doctors Lab (London, UK) or Manchester University NHS Foundation Trust Hospital laboratory (Manchester, UK); normal eosinophil ranges for both laboratories were $<400$ eosinophils $\mu \mathrm{L}^{-1}$. Atopy was determined using skin prick testing and clinical history of childhood asthma, eczema or hay fever.

Statistical analyses were performed using ANOVA or Kruskall-Wallis tests with post-tests as appropriate and Spearman's correlation using GraphPad Prism version 7.00 (San Diego, California, USA). A p-value $<0.05$ was considered statistically significant.

The mean $\pm \mathrm{SD}$ ages were $65.2 \pm 6.8,58.4 \pm 9.6$ and $55.8 \pm 10.2$ years in the COPD, HS and HNS groups respectively $(\mathrm{p}<0.0001)$, with $60 \%, 41 \%$ and $57 \%$ respectively, being male. Forced expiratory volume in $1 \mathrm{~s}$ $\left(\mathrm{FEV}_{1}\right) \%$ predicted was $58.7 \%, 106.1 \%$ and $104.4 \%$ in the COPD, HS and HNS groups respectively. The median smoking history was 42.5 pack-years for COPD patients and 28.5 pack-years for HS. The majority (155 out of 209) of COPD patients were taking ICS treatment. The mean \pm SD modified Medical Research Council (mMRC), COPD Assessment Test (CAT) and COPD-specific St George's Respiratory Questionnaire (SGRQ-C) scores in COPD patients were $2.4 \pm 1.2,20.2 \pm 7.3$ and $49.4 \pm 20.8$ respectively, while 35,24 and $41 \%$ had 0,1 or $\geqslant 2$ exacerbations respectively in the last 12 months.

Blood eosinophil counts were significantly higher in COPD patients compared with HS $(\mathrm{p}<0.01)$ and HNS $(p<0.001)$ (figure 1a); the median blood eosinophil counts were 210,140 and 120 cells $\mu \mathrm{L}^{-1}$ in COPD, HS and HNS, respectively. Total leukocyte count, neutrophil count and monocyte counts were increased in $\operatorname{COPD}\left(7.5 \times 10^{9}, 4.43 \times 10^{9}\right.$ and $0.61 \times 10^{9}$ cells $\cdot \mathrm{L}^{-1}$, respectively) versus $\mathrm{HNS}\left(6.05 \times 10^{9}, 3.47 \times 10^{9}\right.$ and 

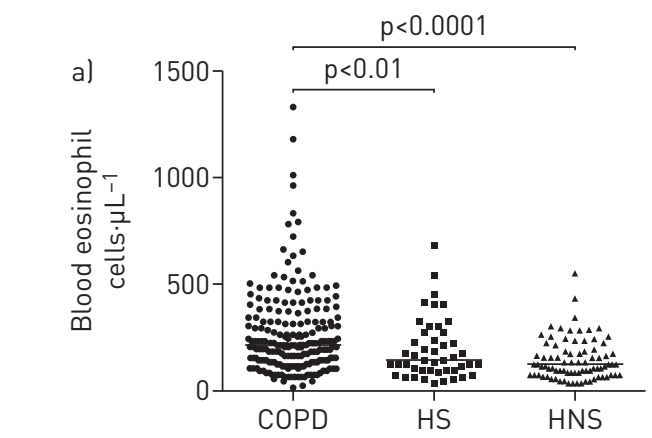

Median cells. $\mu \mathrm{L}^{-1} \quad 210$

140

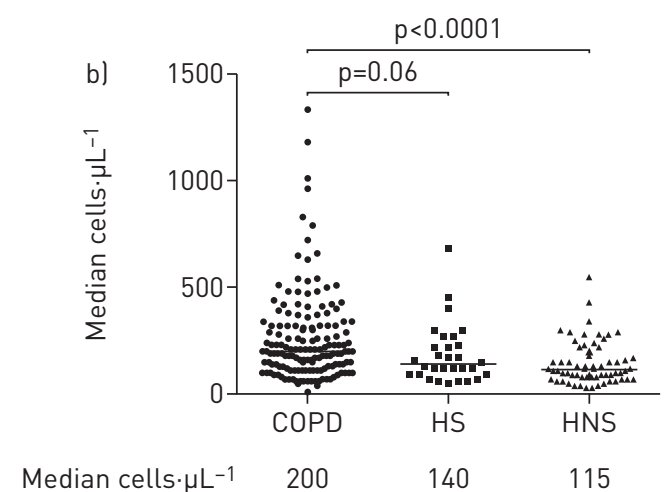

FIGURE 1 The comparison of blood eosinophil counts between COPD, healthy smoker (HS) and healthy nonsmoker (HNS) groups. a) Dot plot includes all subjects including those with a history of atopy. b) Dot plot represents subjects without any history of atopy. Statistical analysis was performed using Kruskal-Wallis and Dunn's multiple comparisons post testing.

$0.50 \times 10^{9}$ cells $\cdot \mathrm{L}^{-1}$, respectively; all $\left.\mathrm{p}<0.0001\right)$ but not $\mathrm{HS}\left(7.75 \times 10^{9}, 4.24 \times 10^{9}\right.$ and $0.61 \times 10^{9}$ cells $\cdot \mathrm{L}^{-1}$, respectively). In COPD patients, there was no correlation between blood neutrophil and eosinophil counts $(\mathrm{p}=0.26)$.

In the COPD group, the proportion of patients with blood eosinophil counts $<100,100-300$ and $\geqslant 300$ cells $\mu \mathrm{L}^{-1}$ was $13 \%, 56 \%$ and $31 \%$, respectively. For the control groups, a lower proportion of individuals had blood eosinophil counts $\geqslant 300$ cells. $\mu \mathrm{L}^{-1} ; 30 \%, 48 \%$ and $22 \%$ of HS blood eosinophil counts $<100,100-300$ and $\geqslant 300$ cells $\mu \mathrm{L}^{-1}$, respectively, while, for HNS the proportions were $40 \%, 55 \%$ and $5 \%$, respectively. $18.7 \%$ of COPD patients compared to $8.7 \%$ and $2.5 \%$ of HS and HNS subjects respectively had a blood eosinophil count above the HNS upper reference interval of $400 \mathrm{cells} \cdot \mu \mathrm{L}^{-1}$. There were no significant correlations between age and blood eosinophil counts in each group (all p $>0.05)$. There were 155 out of 209, 30 out of 46 and 64 out of 81 COPD patients, HS and HNS, respectively, without atopy. Blood eosinophil counts within non-atopic patients showed similar results to the whole group (figure $1 b$ ), with significant differences between COPD patients and HNS ( $p<0.0001$ ), and a trend towards significance between COPD and HS $(p=0.06)$. Blood eosinophil counts were higher in COPD patients using ICS (median: 220 versus 165 cells $\mu \mathrm{L}^{-1} ; \mathrm{p}=0.04$ ). Blood eosinophil counts were similar in COPD current and ex-smokers (225 versus 200 cells $\mu \mathrm{L}^{-1}$, respectively; $\mathrm{p}=0.2$ ).

We have shown that blood eosinophil counts are increased in COPD patients compared with healthy controls. Even when atopic patients were removed from the analysis, similar results were obtained despite a reduction in statistical power that likely contributed to the lack of significance for COPD patients versus HS. The increased eosinophil numbers in the systemic circulation may be a reason for increased lung eosinophil numbers observed in a subgroup of COPD patients $[6,11]$.

The strengths of this study are that the subjects were well characterised (e.g. atopic status, exacerbation history and ICS use) and that all blood counts were obtained in the stable state. Importantly, we also tried to match the ages of the groups. We included all results in subjects aged $>40$ years, but found approximately 7- and 10-year age differences between COPD patients compared with HS and HNS, respectively. We do not believe that this influenced the results, as there was no correlation between age and eosinophil counts. A limitation of this analysis is that the sample sizes for control groups were smaller than the COPD group.

Oral corticosteroids are known to reduce blood eosinophil counts [14]. Here, we observed higher blood eosinophil counts in patients taking ICS. This does not rule out an effect of ICS on blood eosinophil counts, as the cross-sectional nature of our study does not include paired measurements before and after starting ICS treatment. We speculate that perhaps the higher eosinophil counts in ICS users are due to higher eosinophil counts being associated with higher exacerbation rates (observed in other cohort studies [15]), coupled with ICS being used to treat patients with more exacerbations.

We have previously shown that COPD patients with higher blood eosinophil counts also have increased lung eosinophil numbers, and other differences in airway biology including greater reticular basement thickening [11]. The current results support the concept of a subgroup of "eosinophilic COPD" patients, with increased blood and lung eosinophil counts. Eosinophilic COPD appears to be a subgroup (endotype) with unique pulmonary and systemic manifestations, and a differential response to drugs [1-4]. 
Umme Kolsum $^{1}$, Thomas Southworth ${ }^{1,2}$, Natalie Jackson ${ }^{2}$ and Dave Singh ${ }^{1,2}$

${ }^{1}$ The University of Manchester, Division of Infection, Immunity and Respiratory Medicine, School of Biological Sciences, Faculty of Biology, Medicine and Health, Manchester Academic Health Science Centre, Wythenshawe Hospital, Manchester University NHS Foundation Trust, Manchester, UK. ${ }^{2}$ The Medicines Evaluation Unit, The Langley Building, Wythenshawe Hospital, Manchester, UK.

Correspondence: Umme Kolsum, The University of Manchester, Division of Infection, Immunity and Respiratory Medicine, School of Biological Sciences, Faculty of Biology, Medicine and Health, Manchester Academic Health Science Centre, Wythenshawe Hospital, Manchester University NHS Foundation Trust, Manchester, UK. E-mail: ukolsum@meu. org.uk

Received: 29 March 2019 | Accepted after revision: 09 June 2019

Conflict of interest: U. Kolsum has nothing to disclose. T. Southworth is an employee of the Medicines Evaluation Unit. N. Jackson has nothing to disclose. D. Singh reports grants and personal fees from AstraZeneca, Boehringer Ingelheim, Chiesi, GlaxoSmithKline, Glenmark, Menarini, Mundipharma, Novartis, Pfizer, Pulmatrix, Therevance and Verona, and personal fees from Cipla, Genentech and Peptinnovate, outside the submitted work.

Support statement: D. Singh is supported by the NIHR Manchester BRC

\section{References}

1 Vestbo J, Papi A, Corradi M, et al. Single inhaler extrafine triple therapy versus long-acting muscarinic antagonist therapy for chronic obstructive pulmonary disease (TRINITY): a double-blind, parallel group, randomised controlled trial. Lancet 2017; 389: 1919-1929.

2 Bafadhel M, Peterson S, De Blas MA, et al. Predictors of exacerbation risk and response to budesonide in patients with chronic obstructive pulmonary disease: a post-hoc analysis of three randomised trials. Lancet Respir Med 2018; 6: 117-126.

3 Pascoe S, Locantore N, Dransfield MT, et al. Blood eosinophil counts, exacerbations, and response to the addition of inhaled fluticasone furoate to vilanterol in patients with chronic obstructive pulmonary disease: a secondary analysis of data from two parallel randomised controlled trials. Lancet Respir Med 2015; 3: 435-442.

4 Siddiqui SH, Guasconi A, Vestbo J, et al. Blood eosinophils: a biomarker of response to extrafine beclomethasone/ formoterol in chronic obstructive pulmonary disease. Am J Respir Crit Care Med 2015; 192: 523-525.

5 Singh D, Agusti A, Anzueto A, et al. Global Strategy for the Diagnosis, Management, and Prevention of Chronic Obstructive Lung Disease: The GOLD Science Committee Report 2019. Eur Respir J 2019; 53: 1900164.

6 Brightling CE, McKenna S, Hargadon B, et al. Sputum eosinophilia and the short term response to inhaled mometasone in chronic obstructive pulmonary disease. Thorax 2005; 60: 193-198.

7 Saha S, Brightling CE. Eosinophilic airway inflammation in COPD. Int J Chron Obstruct Pulmon Dis 2006; 1: 39-47.

8 Singh D, Kolsum U, Brightling CE, et al. Eosinophilic inflammation in COPD: prevalence and clinical characteristics. Eur Respir J 2014; 44: 1697-1700.

9 Eltboli O, Mistry V, Barker B, et al. Relationship between blood and bronchial submucosal eosinophilia and reticular basement membrane thickening in chronic obstructive pulmonary disease. Respirology 2015; 20: 667-670.

10 Kolsum U, Donaldson GC, Singh R, et al. Blood and sputum eosinophils in COPD; relationship with bacterial load. Respir Res 2017; 18: 88.

11 Kolsum U, Damera G, Pham TH, et al. Pulmonary inflammation in patients with chronic obstructive pulmonary disease with higher blood eosinophil counts. J Allergy Clin Immunol 2017; 140: 1181-1184 e7.

12 Bafadhel M, McKenna S, Terry S, et al. Blood eosinophils to direct corticosteroid treatment of exacerbations of chronic obstructive pulmonary disease: a randomized placebo-controlled trial. Am J Respir Crit Care Med 2012; 186: 48-55.

13 Vogelmeier CF, Criner GJ, Martinez FJ, et al. Global Strategy for the Diagnosis, Management, and Prevention of Chronic Obstructive Lung Disease 2017 Report: GOLD Executive Summary. Eur Respir J 2017; 49: 1700214.

14 Thorn GW, Renold AE, Wilson DL, et al. Clinical studies on the activity of orally administered cortisone. $N$ Engl $J$ Med 1951; 245: 549-555.

15 Yun JH, Lamb A, Chase R, et al. Blood eosinophil count thresholds and exacerbations in patients with chronic obstructive pulmonary disease. J Allergy Clin Immunol 2018; 141: 2037-2047 e10. 